\title{
Trends in Neonatal Mortality at a Tertiary Level Teaching Hospital
}

\author{
Basnet $\mathbf{S}^{1}$, Shrestha $\mathrm{L}^{2}$ \\ ${ }^{1}$ Dr. Srijana Basnet, MBBS, MD, Assistant Professor. \\ ${ }^{2}$ Dr. Laxman Shrestha, MBBS, MD, Associate Professor. \\ Both from the Department of Paediatrics, Institute of \\ Medicine, Tribhuvan University Teaching Hospital, \\ Maharajgunj, Kathmandu, Nepal
}

\section{Introduction}

A dvances in neonatal care have significantly increased survival and decreased morbidity among infants admitted to neonatal intensive care units $(\mathrm{NICUs})^{1}$.

There are, however, significant variations in outcomes among NICUs ${ }^{2}$. Tribhuvan University Teaching hospital, the oldest medical college of Nepal is a tertiary care multidisciplinary hospital having 460 beds. It was established in the year 1972 and from its establishment it is providing obstetric services. It is a referral centre for obstetrics services where high-risk pregnant women are referred from throughout the country. However, neonatal service was started only in the year 1994 and neonatal care was essentially level II up to year 2008.With the increasing obstetrics referrals and large number of preterm deliveries, the existing neonatal services was upgraded to level III NICU. During this process in the year 2008, various equipments including monitors, syringe pumps, radiant warmer, incubators, CPAP, ventilators were added to the neonatal unit. The number of nursing staffs was increased to provide level III care from the year 2009 .

At present, in neonatal unit there are three ventilators, several CPAP circuits, and three cardiothoracic monitors. Two paediatric residents are posted in rotation in neonatal ward throughout the year. There are all together 12 neonatal nursing staffs. Well babies and babies with minor problems like neonatal jaundice, suspected sepsis get treatment in postnatal ward.

\author{
Address for correspondence \\ Dr. Srijana Basnet \\ Assistant Professor, Department of Paediatrics, \\ Institute of Medicine, Tribhuvan University Teaching Hospital, \\ Maharajgunj, Kathmandu, Nepal \\ E-mail: drsrijanabasnet@yahoomail.com
}

\begin{abstract}
Introduction: Neonatal services at Tribhuvan University Teaching hospital (TUTH) was essentially up to level II till year 2008 and upgraded to level III care in later years. A 4 years retrospective study was carried out at TUTH, Kathmandu, Nepal to determine any change in the trend of neonatal mortality after the improvement in its services. Materials and Methods: Labor room record book, neonatal record book, perinatal audit data and neonatal record charts were used to collect the data. Results: During the study period, there were total of 15063 live births. The neonatal mortality ranges from 9.46 to 14.88 per 1000 live births per year. There was no significant fall in trend of neonatal mortality $\left(x^{2}\right.$ for linear trend=1.40, $p=0.23$ ). There was also no significant fall in trend in perinatal mortality rates over this period ( $x^{2}$ for linear trend $=1.92$, $p=0.16)$. The number of neonates referred to other hospitals has been significantly reduced by 61 \%. ( $x 2$ for linear trend=33.18, $p<0.001)$. Majority of the neonatal deaths $(72 \%)$ occurred within first 7 days of life and more than a third (39\%) died within the first 24 hours of life. Respiratory distress syndrome, perinatal asphyxia and neonatal sepsis were three major causes of death. Deaths due to respiratory distress and perinatal asphyxia has not changed significantly over the years $(p=0.4$ and 0.25 respectively). Incidence of low birth weight ranges from $10.8-16.1 \%$ of total live births. $63 \%$ of neonatal mortality occurred in low birth weight babies. This trend has not changed in over the years $\left(x^{2}=1.03, p=0.31\right)$. Conclusion: With the improvement in the services, though neonatal mortality remained unchanged, referral rates and mortality due to respiratory distress syndrome of prematurity has decreased.
\end{abstract}

Key words: neonatal mortality, prematurity, asphyxia

\section{How to cite this article?}

Basnet S, Shrestha L. Trends in Neonatal Mortality at a Tertiary Level Teaching Hospital. J Nepal Paediatr Soc 2013;33(3):213217. 
As neonatal services were upgraded for last few years, it was time to analyze whether these measures have helped to improve neonatal care and survival. The neonatal mortality rates reflect the efficiency and effectiveness of health care services so this important indicator is used in this study. Indicators like neonatal mortality and perinatal mortality are also useful in planning for improved healthcare delivery ${ }^{3}$. It is important to review the pattern of neonatal morbidities and mortality at regular intervals so that neonatal care could be improved ${ }^{4}$. Therefore, this study was carried out with the objectives to analyze the trend of neonatal mortality and to see pattern of neonatal morbidities at neonatal unit of TUTH.

\section{Materials and Methods}

This is a retrospective descriptive study from April 2007 to April 2011 done at neonatal ward of TUTH. Labor room record book, neonatal record book, perinatal audit datas and neonatal record charts were used to collect the data. Data and figures of hospital deliveries, total live births, still births, gestational age, birth weight, first week deaths, neonatal deaths and causes of death were recorded. The number of babies referred to other centers was also recorded. All these yearly data were compared using $\mathrm{x}^{2}$ test with Stat direct software.

\section{Result}

From 2007 April to 2011 April, total of 15063 live babies were delivered at TUTH. Thirteen percent of these newborns required admission in neonatal unit. The yearly distribution of number of admitted newborns and referred newborn is shown in Table 1. There was no significant increase in number of neonatal admission in neonatal unit $\left(x^{2}\right.$ for linear trend $=1.40, p=0.23$ ) over these years.

The yearly distribution of birth as well as total number of neonatal death is shown in table 2 .
The neonatal mortality ranges from 9.45 to 14.88 per 1000 live births per year (Figure 1).

There was no significant fall in trend in neonatal mortality rates over this 4 year period $\left(x^{2}\right.$ for linear trend=1.46, $p=0.23$ ).

The perinatal mortality rate over this period ranges from 15.59 to 20.24 per 1000 total births (table 3 and figure 2). There was also no significant fall in trend in perinatal mortality rates. $\left(x^{2}\right.$ for linear trend $=1.92, p=$ 0.16).

The number of neonates referred to other hospitals has been significantly reduced by $61 \%$.( $x 2$ for linear trend $=33.18, p<0.001)$. Majority of the neonatal deaths (72\%) occurred within first 7 days of life and more than a third $(39 \%)$ died within the first 24 hours of life (figure 3 ).

Yearly distribution of $1^{\text {st }}$ day neonatal death as proportion of early neonatal death is illustrated in figure 3 .

Respiratory distress syndrome, perinatal asphyxia and sepsis were three major causes of neonatal deaths (fig 4). In recent years, early deaths due to respiratory distress syndrome and prematurity have gradually decreased from $33 \%$ to $25 \%$ whereas neonatal mortality due to perinatal asphyxia has increased from $41 \%$ to $51 \%$. The trend for these mortalities have not changed significantly over 4 year period ( $x^{2}$ for respiratory distress syndrome $=1.07, p=0.2, x^{2}$ for perinatal asphyxia $=1.47$ and $p=0.22$ ). Ninety percent of mortality after $1^{\text {st }}$ week occurred due to neonatal sepsis.

Incidence of low birth weight babies ranges from $10.8-16.1 \%$ of total live birth (table 4 ).

$63 \%$ of early neonatal mortality occurred in low birth weight babies and the mortality trend of low birth weight babies has not changed over these years $\left(x^{2}=1.03, p=0.31\right)$.

Table 1: Live births, neonatal admission and referral at TUTH (2007-2011)

\begin{tabular}{|c|c|c|c|}
\hline Year & Live births & $\begin{array}{c}\text { Neonatal admission } \\
\text { (\% of live birth) }\end{array}$ & Referral \\
\hline $2007-2008$ & 3949 & $477(15.98 \%)$ & 36 \\
\hline $2008-2009$ & 3773 & $499(13.22 \%)$ & 40 \\
\hline $2009-2010$ & 3452 & $467(13.4 \%)$ & 14 \\
\hline $2010-2011$ & 3889 & $516(13.11 \%)$ & 5 \\
\hline
\end{tabular}


Table 2: Live births, Neonatal deaths, Neonatal mortality rates at TUTH (2007-2011)

\begin{tabular}{|c|c|c|c|c|c|c|}
\hline Year & $\begin{array}{c}\text { Live } \\
\text { births }\end{array}$ & $\begin{array}{c}\text { Early neonatal } \\
\text { deaths }\end{array}$ & $\begin{array}{c}\text { Total } \\
\text { NND }\end{array}$ & $\begin{array}{c}\text { Total Neonatal } \\
\text { mortality per } \mathbf{1 0 0 0} \\
\text { live births }\end{array}$ & $\begin{array}{c}\text { Early Neonatal } \\
\text { mortality per } \mathbf{1 0 0 0} \\
\text { live births }\end{array}$ & $\begin{array}{c}\text { Total Neonatal } \\
\text { mortality } \mathbf{9 5 \%} \mathbf{~ C l}\end{array}$ \\
\hline $2007-2008$ & 3949 & 24 & 36 & 9.45 & 6.07 & $6.41-12.48$ \\
\hline $2008-2009$ & 3773 & 33 & 40 & 11.04 & 8.74 & $7.65-14.39$ \\
\hline $2009-2010$ & 3452 & 35 & 52 & 14.88 & 10.13 & $6.43-23.32$ \\
\hline $2010-2011$ & 3889 & 31 & 42 & 10.71 & 7.77 & $7.45-13.96$ \\
\hline Total & $\mathbf{1 5 0 6 3}$ & $\mathbf{1 2 3}$ & $\mathbf{1 7 0}$ & - & - & - \\
\hline
\end{tabular}

Table 3: Perinatal mortality at TUTH (2007-2011)

\begin{tabular}{|c|c|c|c|c|c|c|}
\hline Year & Total birth & Still births & Early NND & $\begin{array}{c}\text { Still births + } \\
\text { Early NND }\end{array}$ & PMR & $\mathbf{9 5 \%}$ Cl \\
\hline $2007-2008$ & 3986 & 37 & 25 & 62 & 15.59 & $11.71-19.46$ \\
\hline $2008-2009$ & 3814 & 41 & 36 & 77 & 20.24 & $15.72-24.75$ \\
\hline $2009-2010$ & 3487 & 35 & 35 & 70 & 20.09 & $15.38-24.79$ \\
\hline $2010-2011$ & 3937 & 48 & 31 & 79 & 20.11 & $15.68-24.11$ \\
\hline
\end{tabular}

Table 4: Total LBW and preterm LBW babies

\begin{tabular}{|c|c|c|c|c|c|}
\hline Year & $\begin{array}{c}\text { Total LBW } \\
\text { babies }\end{array}$ & Preterm LBW & Total live births & $\begin{array}{c}\text { Rate of LBW per } \\
\mathbf{1 0 0 0}\end{array}$ & Preterm LBW (\%) \\
\hline $2007-2008$ & 483 & 282 & 3986 & 161.75 & 9.14 \\
\hline $2008-2009$ & 470 & 257 & 3814 & 123.23 & 6.73 \\
\hline $2009-2010$ & 459 & 246 & 3487 & 131.68 & 7.05 \\
\hline $2010-2011$ & 428 & 242 & 3937 & 108.71 & 6.14 \\
\hline
\end{tabular}

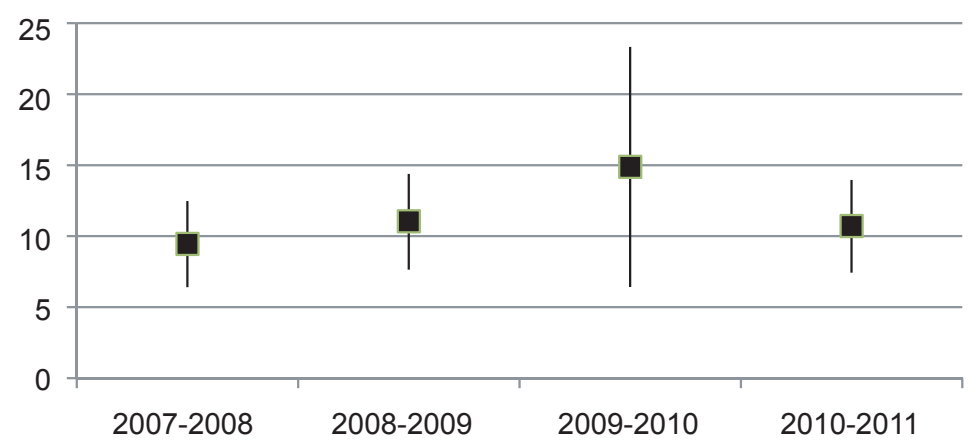

Fig 1: Total neonatal mortality at TUTH with 95\% Cl (2007-2011)

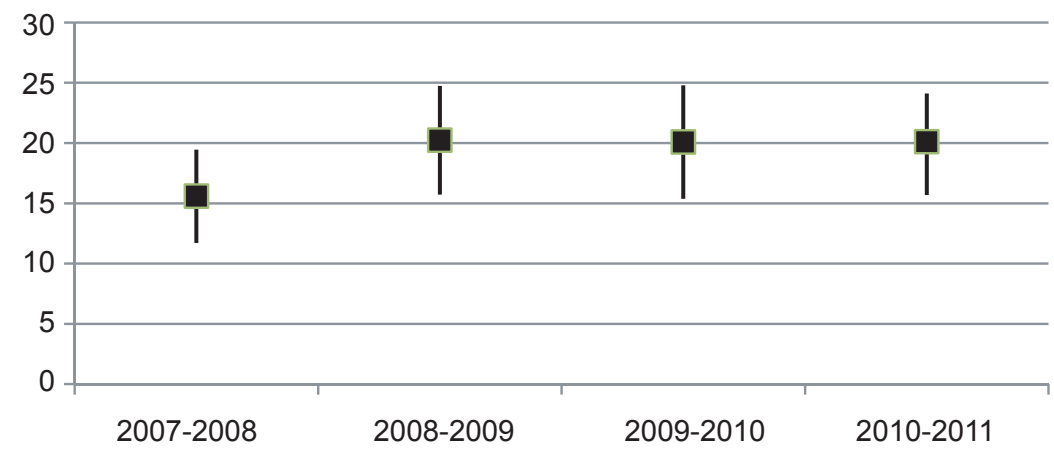

Fig 2: Perinatal mortality at TUTH (2007-2011) 


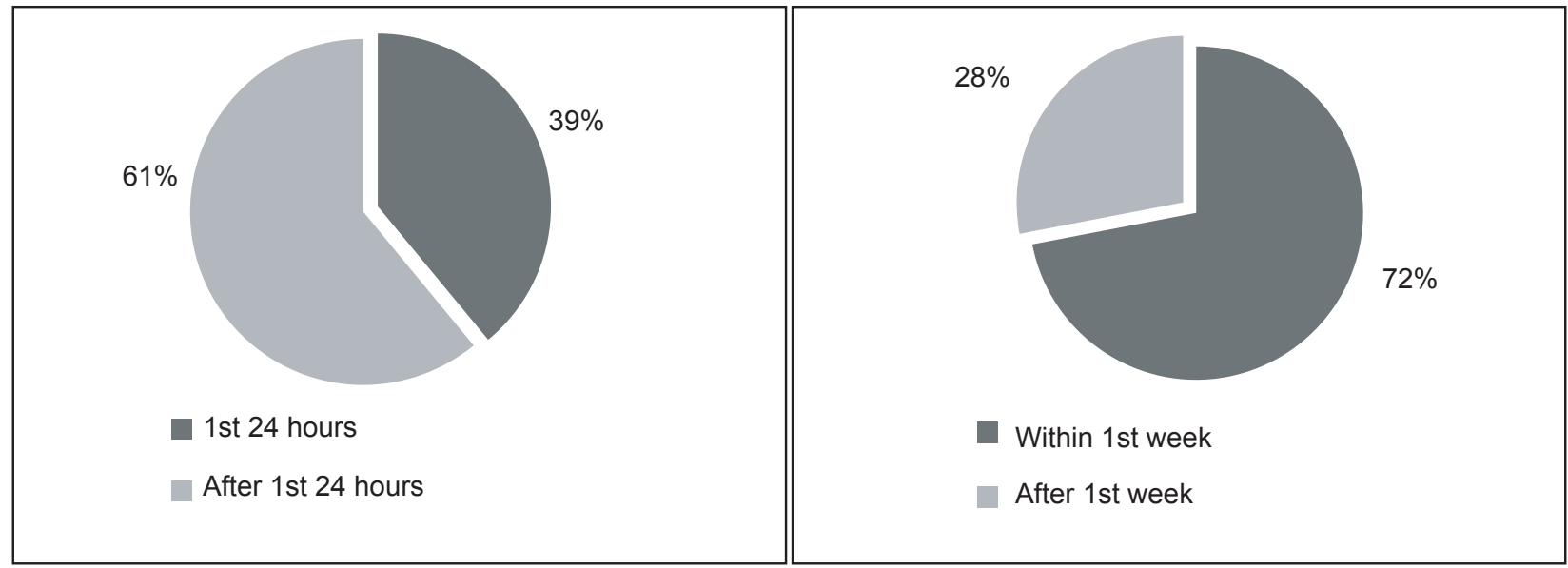

Fig 3: First week and first day neonatal deaths

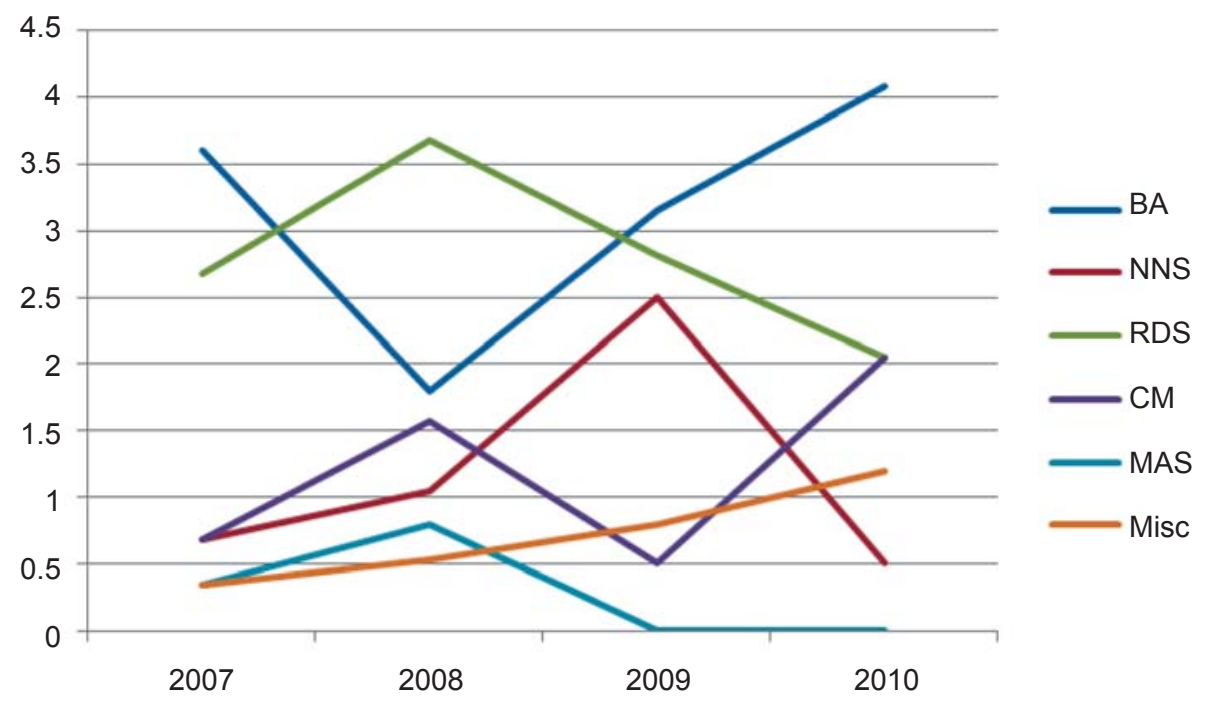

Fig 4: Different causes of early neonatal mortality per 1000 births

$\mathrm{BA}=$ Birth asphyxia, NNS=Neonatal sepsis, RDS=Respiratory distress syndrome

$\mathrm{CM}=$ Congenital malformation, MAS=Meconium aspiration syndrome

\section{Discussion}

The present study describes the trend in neonatal mortality at TU Teaching Hospital over a period of four years. Neonatal mortality of Nepal in 2006 is 33 per 1000 live births ${ }^{5}$. During the study period, neonatal mortality rate of TUTH range from 6.07-10.13/1000 live births which is comparable with the other hospitals of Kathmandu valley during same time $e^{6,7,8}$. The global estimation of PMR is 10 per 1000 births in developed countries, 50 per 1000 births in developing countries and 60 per 1000 births in least developed countries ${ }^{9}$. At Tribhuvan University Teaching Hospital (TUTH) during the study period PMR ranged from 15-20 per 1000 births which has remained unchanged as over previous years ${ }^{10}$.PMR in different hospitals of the Kathmandu valley during these years ranges from 31.3 to 14.4 per 100 births $^{6,7,8,11}$.
Prematurity, asphyxia and septicemia were three main causes of early neonatal deaths. During the study period, $41-51 \%$ of early neonatal mortality occurred due to perinatal asphyxia and $25-33 \%$ of early neonatal mortality occurred due to respiratory distress syndrome of prematurity. This finding is comparable to the similar study ${ }^{12}$ done in College of Medical Science, Bharatpur which showed $48.0 \%$ of neonatal death is due to birth asphyxia, $29.0 \%$ due to neonatal sepsis and $22.0 \%$ due to prematurity. A population based cohort study ${ }^{13}$ done in Southern Nepal showed $30.0 \%$ of NND is due to birth asphyxia. Similar study ${ }^{14}$ done at Patan Hospital revealed $30.0 \%$ on early neonatal death was due to respiratory distress syndrome, $25.0 \%$ due to neonatal sepsis, $16.0 \%$ due to congenital anomalies and $13.0 \%$ due to birth asphyxia. This indicates that mortality due to perinatal asphyxia is more frequent in TUTH than in Patan hospital. According to the World 
Health Organization (WHO), between four and nine million newborns develop birth asphyxia each year. Of those, an estimated 1.2 million die and at least the same number develop severe consequences, such as epilepsy, cerebral palsy, and developmental delay ${ }^{15}$. The proportion of perinatal asphyxia is quite high for tertiary level hospital and its increasing trend warrants improvement in intrapartum monitoring and obstetric services at TUTH. The mortality trend of low birth weight babies has not changed over these years $\left(x^{2}=1.03, p=0.31\right)$, though the deaths due to respiratory distress have decreased. There is significant reduction in number of referrals too. Increased use of antenatal corticoids and advancements in the field of assisted ventilation played a role to decrease neonatal mortality due to respiratory distress. Neonatal sepsis was main contributor for late neonatal death which necessitates strict adherence to infection control measure.

Advancing intensive care technologies is closely associated with improve survival in low birth weights. ${ }^{16}$ With the easy access to surfactant and advancements in the field of assisted ventilation, increased survival of low birth weight babies is expected at TUTH in future.

\section{Conclusion}

Even with improvement in the services, the neonatal mortality rate remained unchanged. The referral rate has been significantly reduced and mortality due to respiratory distress syndrome of prematurity has decreased. Perinatal asphyxia and neonatal sepsis are still the major causes of neonatal mortalities. Neonatal services have to be further improved to decrease of neonatal mortalities significantly.

Acknowledgment: We would like to thank all staff of NICU who helped me collecting data.

Conflict of Interest: None

Funding: None

Permission from IRB: Not required

\section{References}

1. Lee KS, Paneth N, Gartner LM, Pearlman MA, Gruss L. Neonatal mortality: an analysis of the recent improvement in the United States. Am J Public Health 1980;70:15-21.

2. Williams RL, Chen PM. Identifying the sources of the recent decline in perinatal mortality rates in California. N Engl J Med 1982;306:207-214.

3. Shoo K. Lee, Douglas D. McMillan, Arne Ohlsson, Margaret Pendray, Anne Synnes, Variations in Practice and Outcomes in the Canadian NICU Network: 1996-1997. Pediatrics 2000;106;10701079.
4. Omoigberale AI, Sadoh WE, Nwaneri DU. A 4 year review of neonatal outcome at the University of Benin Teaching Hospital, Benin City. Niger J Clin Pract 2010;13(3):321-5.

5. Ministry of health $(\mathrm{MoH})$, Annual report. Department of health services. Nepal demographic and health survey 2006. Available from http://www. measuredhs.com/pubs

6. Shah $\mathrm{G}$ and Adhikari N. One year perinatal mortality review of 9. Patan hospital. In: Satyal I editor. Proceedings of the 6th Conference of Perinatal Society of Nepal; 2008. p.34

7. Shrestha $S$, Sharma A, Upadhyay $S$ and Rijal P. Perinatal mortality audit. Nepal Med Coll J 2010; 12(4):257-9.

8. SR Manadhar,DS Manadhar, J shrestha et al. Analysis of Perinatal Deaths and Ascertaining Perinatal Mortality Trend in a Hospital. J Nepal Health Res Counc 2011; 9(19):150-53.

9. Neonatal and Perinatal Mortality. Country, Regional and Global estimates : World Health Organization; 2006.Available from http://www. who. int/publications/2007

10. Shrestha M, Shrestha L, Basnet S, Shrestha PS. Trends in Perinatal Mortality in Tribhuvan University Teaching Hospital: 13 Years Review. J Nepal Paediatr Soc 2012;32(2):150-153.

11. Aryal DR and Satyal I. Perinatal mortality at Paropakar maternity and women's hospital, Kathmandu. In: Dhakhwa JR editor. Souvenir of 7th Conference of Perinatal Society of Nepal. 7th ed. Kathmandu: PESON; 2009. p. 94-95.

12. Gurubacharya SM, Gurubacharya RL. An overview of neonatal admission at College of Medical Sciences. Nepal Paediatr Soc J 2007;27:73-4.

13. LeClerq SC, Adhikari RK, Shrestha SR, Darmstadt GL. Risk factors for neonatal mortality due to birth asphyxia in Southern Nepal. Pediatr $J$ 2008;121:1381-90.

14. Shrestha S, Adhikari N. Causes of neonatal deaths at Patan Hospital. J Nepal Health Res Counc 2002: 27-31.

15. Save the children. Washington DC: Saving Newborn Lives; The state of the world's newborn: a report from saving newborn lives. 2001; 1-44. Available from http://www.healthynewbornnetwork. org/resource/state-worlds-newborns

16. Richardson D K, Gray J E, Gortmaker S L, Goldmann D A, Pursley D M, McCormick M C. Declining severity adjusted mortality: evidence of improving neonatal intensive care. Pediatrics 1998;102:893-9. 